\title{
Spatial distribution of heavy metals in soils and plants in Zinc Town, northwest Iran
}

\author{
M. A. Delavar ${ }^{1} \cdot$ Y. Safari ${ }^{1}$
}

Received: 16 May 2014/Revised: 22 February 2015/Accepted: 14 July 2015/Published online: 30 July 2015

(C) Islamic Azad University (IAU) 2015

\begin{abstract}
Identification of heavy metals spatial variability in soil and plants may provide useful information on how to manage the polluted sites. The main objective of this study was to determine the spatial distribution of selected heavy metals in soils and natural plants of Zanjan city, northwest Iran. A total of 184 composite topsoil samples $(0-10 \mathrm{~cm})$ and 98 natural plant samples were systematically taken from an area of about 4000 ha located around an industrial complex, covering rangeland and agricultural and industrial land uses. All samples were analyzed for their total concentration of $\mathrm{Zn}, \mathrm{Pb}$ and $\mathrm{Cd}$. The results showed that the average concentrations of $\mathrm{Zn}, \mathrm{Pb}$ and $\mathrm{Cd}$ in the soil samples were up to 294.2, 152.8 and $5.6 \mathrm{mg} \mathrm{kg}^{-1}$, respectively, whereas in the plant samples, these values decreased to $131.4,113.2$ and $2.5 \mathrm{mg} \mathrm{kg}^{-1}$, respectively. These contents are much higher than the normal range in soil and plant communities, leading to classify the studied area as a polluted site. Variography analyses revealed a similar spatial structure for the studied heavy metals in the soil and plant samples. Based on interpolated maps, the highest concentrations of the selected heavy metals in the soil and plant samples were found in the vicinity of industrial complex. These findings clearly highlight the role of industrial activities in simplifying the entrance of dangerous trace elements to the human food chain. Application of ordinary kriging technique to predict the heavy metals spatial variability in the plant community resulted in logical estimations with acceptable error values.
\end{abstract}

M. A. Delavar

amir-delavar@znu.ac.ir

1 Soil Science Department, College of Agriculture, University of Zanjan, P.O. Box 45371-38791, Zanjan, Iran
Keywords Heavy metals · Industrial activities · Ordinary kriging · Spatial variability

\section{Introduction}

Soil as the most important human food resource serves as both a sink and a source for heavy metal (HM) pollutants (Sun et al. 2010). These pollutants are generally discharged into soil by industrial activities (Alloway 1995; Möller et al. 2005), agricultural additives (Pang et al. 2011) and various urban activities (Jing et al. 2007). Concentrated HMs in soils may present a serious risk of human health because they are non-degradable pollutants with a large spectrum of negative effects (e.g., nervous or digestive system disturbances and carcinogenic effects) (Maas et al. 2010). Contaminated urban soils directly expose humans to HMs due to their close proximity to human activities (Sun et al. 2010), whereas agricultural soils rich in HMs play this role indirectly due to possible transfer of metals through food webs (Burger 2008). Hence, determining the spatial distribution pattern of metal pollutants in soils for human and ecological risk assessment is necessary.

Such spatial data help environmental scientists in defining the areas where risks are high and decision makers in identifying locations where remedial efforts should be made (Li et al. 2009). Because of the complexity of the soil body and various resources of HMs, these pollutants vary greatly over the land surface, and their distribution patterns generally have high spatial heterogeneity, paralleling variations in pedological parameters (Maas et al. 2010). Thus, it is very difficult to acquire an accurate spatial distribution pattern of HMs (Xie et al. 2011). Considering the insufficiency of classical statistics to reveal the spatial autocorrelation of soil pollutants (Hu et al. 2006), many 
researchers have focused on and referred to new techniques like geographical information systems (GIS) and geostatistical methods as more useful approaches (Wu et al. 2008; Maas et al. 2010; Karanlik et al. 2011; Pang et al. 2011; Dankoub et al. 2012; Guo et al. 2012; Li et al. 2013). The main advantage of geostatistical method is its unbiased estimation of variable values for spatial objects at notsampled locations, i.e., interpolation (Goovaerts 1999; Webster and Oliver 2001).

Geostatistics is a powerful interpolation tool that can quantify and reduce sampling uncertainties, minimize investigation costs (Wu et al. 2008) and as well provide a set of statistical tools popularly applied in surveys of soil contamination (Zhang et al. 2008). Using geostatistical estimators, e.g., different kriging methods, spatial variability of soil contaminants can be displayed as a continuous map. This detailed information about HMs distribution pattern in the soils with different land uses assists in developing strategies to protect urban environments and human health against long-term accumulation of HMs (Guo et al. 2012). Although geostatistics is used commonly for risk assessment in contaminated soils, few studies have been carried out to describe the spatial distribution of HMs in natural or cultivated plants on polluted sites.

The process of HMs uptake by various plants is influenced by such different factors as plant species (Alloway et al. 1990), physicochemical soil properties (Qian et al. 1996) and elements concentrations (Thornton 1999). The presence of high levels of HMs in soils, however, exerts a selection pressure on plant populations leading to extra uptake of HMs (Ghaderian and Ghotbi Ravandi 2012). Hence, it is predictable that HMs distribution pattern in the soil affects the spatial distribution of these elements in natural plants grown in the polluted soil without regard to complexity of the plant communities. Therefore, we tested this hypothesis (accurately described by geostatistics) that the spatial distribution of selected metal elements has a similar trend in the soil and plant communities.

Zinc Specialized Industrial Town (briefly Zinc Town), located in the south of Zanjan city, northwest Iran, is one of the most productive metallurgical plants in the country. This industrial complex was established in 1996 with a current consumption of about one million tons of raw ore and a production of 0.19 million tons of Zinc $(\mathrm{Zn})$ per year. It is located $6 \mathrm{~km}$ southwest of the city and produces high volumes of metallic wastes undesirably collected around the town; thus, contamination of the adjacent environment consisting of air, soil and plant communities with HMs is almost unavoidable. The main objectives of this study were first to determine the concentration and distribution of $\mathrm{Zn}$, lead $(\mathrm{Pb})$ and cadmium $(\mathrm{Cd})$ in the soils and natural plants of the studied area and then to assess the efficiency of geostatistics in revealing HMs spatial variability in plant community.

\section{Materials and methods}

\section{Study area}

The area under investigation has a size of approximately 4000 ha. It is located between $36^{\circ} 35^{\prime}$ and $36^{\circ} 40^{\prime}$ north and $48^{\circ} 24^{\prime}$ and $48^{\circ} 28^{\prime}$ east in Zinc Town and the surrounding lands, Zanjan Province, northwest Iran (Fig. 1). This area has a semiarid climate with an average annual temperature of $11.5^{\circ} \mathrm{C}$ and rainfall of more than $300 \mathrm{~mm}$. Old alluvial fans are the main geomorphologic unit of the study area, and the soils under investigation have generally been formed on Quaternary alluvial and colluvial deposits. Rangeland and agricultural and industrial areas are major land uses in this area (Fig. 1). Hulthemia persica, Alhagi maurorum, Ephorbia macroclada and Cardaria draba are the main endemic plant species in the area. Among these natural plant species, the herbaceous annual plant of $H$. persica was recognized as the dominant species in the studied area and was used for assessing the HMs spatial distribution pattern in the natural plant community. Plant samples were collected from all locations that $H$. persica existed (Fig. 1).

\section{Sample collection and analyses}

The sampling points were systematically distributed in the lands surrounding Zinc Town, based on a regular grid sampling method $500 \times 500 \mathrm{~m}$, which is the most usual sampling approach for geostatistical purposes (Webster and Oliver 2001). Thus, 184 grid cells were sampled (Fig. 1). Within each cell, five subsamples (to obtain a representative sample) were collected from the topsoil $(0-10 \mathrm{~cm})$. Besides, plant samples from the areal parts of H. Persica as the dominant endemic plant species were collected at all sampling points (98 points) located in the rangeland sites; areas consist of a combination of rangeland and agricultural land uses. All the soil and plant samples were collected in August and September 2012.

Soil samples were air-dried and sieved through a 2-mm plastic sieve for removal of large debris, plant roots, gravel-sized and other waste materials. The samples were digested with a 5:2:3 mixture of $\mathrm{HNO}_{3}-\mathrm{HCLO}_{4} / \mathrm{HF}$ ( $\mathrm{Li}$ et al. 2012). For the analysis of plant dry matter, leaf materials were washed well with double-distilled water and dried at $70{ }^{\circ} \mathrm{C}$ for $48 \mathrm{~h}$. About $1 \mathrm{~g}$ of dry leaf sample was added to a $25-\mathrm{ml}$ beaker and burned to ash in a muffle furnace for $14 \mathrm{~h}$ at $480{ }^{\circ} \mathrm{C}$. The ash was taken up in $5 \mathrm{ml}$ $10 \% \mathrm{HNO}_{3}$, and the digest was finally made up to $20 \mathrm{ml}$ in 
Fig. 1 Map of the study area along with sampling points under different land uses

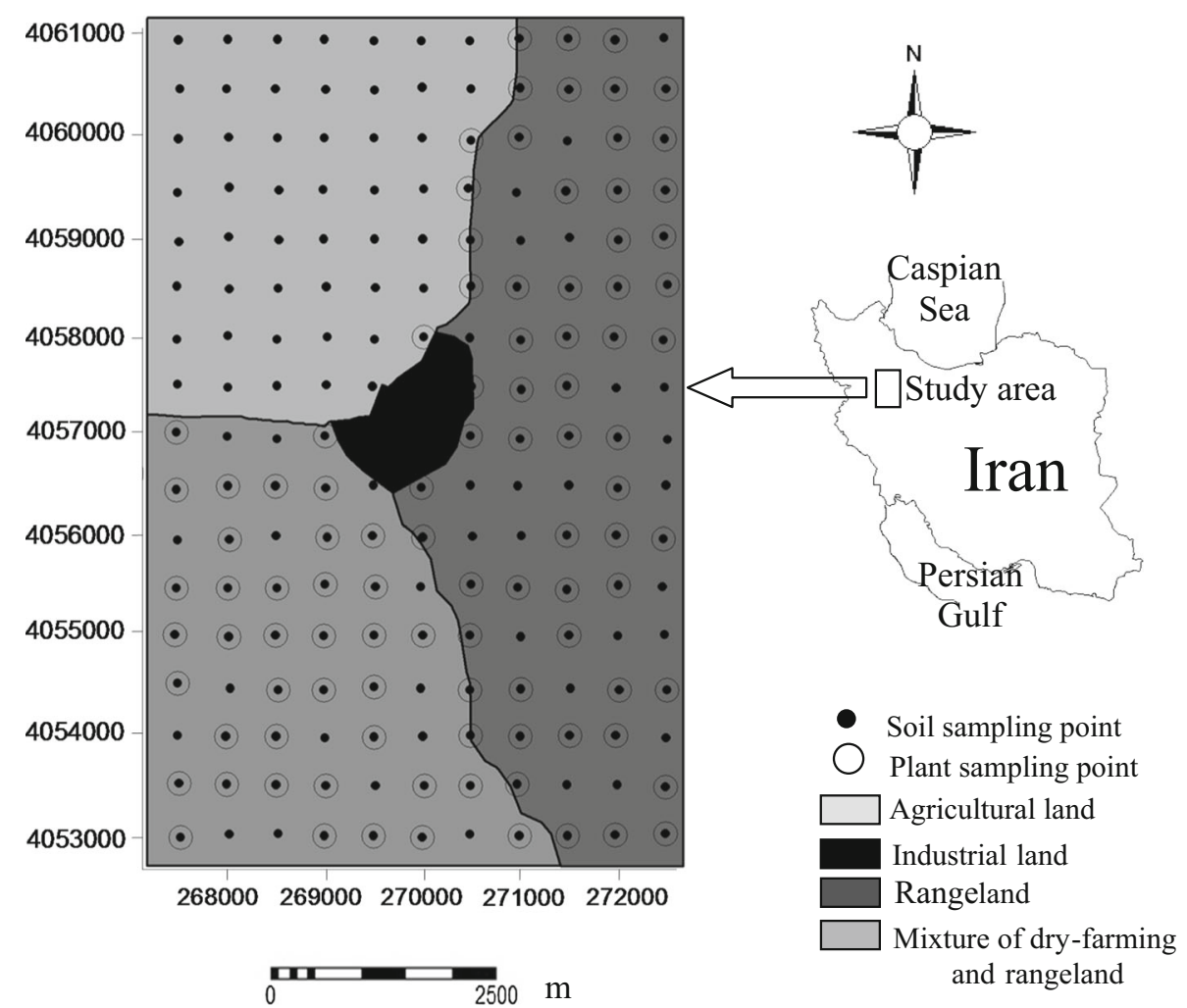

$10 \% \mathrm{HNO}_{3}$. All of the plant and soil digested solutions were analyzed via atomic absorption spectroscopy for their total concentrations of $\mathrm{Pb}, \mathrm{Zn}$ and $\mathrm{Cd}$.

\section{Data processing}

\section{Statistical analysis}

Descriptive statistics including minimum, maximum, mean, standard deviation, skewness and kurtosis were determined using the SPSS software version 17.0 for Windows. The normality of data was checked by the Kolmogorov-Smirnov (K-S) test. Since serious violation of normality can impair the quality of geostatistical results (Webster and Oliver 2001), the abnormal data series were transformed to normal distribution.

\section{Geostatistical studies}

Geostatistics provides a set of statistical tools for incorporating the spatial and temporal coordinates of observations in data processing, and its increasing use in environmental applications testifies to its utility and success (Saito and Goovaerts 2000). Semivariogram, functioning as the basic tool of geostatistics, is the mathematical expression of the square of regional variables $Z\left(x_{i}\right)$ and $Z\left(x_{i}+h\right)$, namely the variance of regional variables. Semivariogram $\gamma(h)$ is computed as half of the average squared difference between the components of data pairs (Goovaerts 1999):

$\gamma(h)=\frac{1}{2 N(h)} \sum_{i=1}^{N(h)}\left[Z\left(x_{i}\right)-Z\left(x_{i}+h\right)\right]^{2}$

where $N(h)$ is the number of sample value pairs within the distance interval $h ; Z\left(x_{i}\right)$ and $Z\left(x_{i}+h\right)$ are sample values at two points separated by the distance interval $h$.

The semivariogram function is used by geostatistical interpolation methods to quantify the spatial variability of regionalized variables. Ordinary kriging $(\mathrm{OK})$, as the most common geostatistical estimator, provides an estimate for the whole area around a measured point. The OK estimator is expressed as (Webster and Oliver 2001):

$Z^{*}\left(x_{0}\right)=\sum_{i=1}^{n} \lambda_{i} Z\left(x_{i}\right)$

where $Z^{*}\left(x_{0}\right)$ and $\lambda_{i}$ are the estimated values of variable $Z$ at location $x_{0}$ and the associated weight with the measured value of $Z$ at location $x_{i}$, respectively. The weights are assigned to the observed values so that the estimated error variance is minimized. Interpolated maps of HMs spatial distribution were generated using Surfer software version 9 . 
In order to check the validity of performed estimations, the jack-knifing technique, the common technique of assessing the predictive capability of different regression models (Lesch and Corwin 2008), was used. Consequently, interpolated and actual (observed) values were compared using the error measurement of standardized root-meansquare error (RMSE \%), which is calculated as follows (Hengl et al. 2004):

$\operatorname{RMSE} \%=100 \times \frac{\sqrt{\frac{\sum\left(x^{\prime}-x\right)^{2}}{n}}}{\bar{X}}$

where $n$ is the number of observations, $\bar{X}$ is average of the observed values, and $x^{\prime}$ and $x$ are estimated and observed values, respectively.

\section{Results and discussion}

\section{Statistical analyses of HMs contents in the soil and plant samples}

Table 1 presents the descriptive statistics of the studied HMs concentrations in the soil and plant samples.

There was a remarkable change in the content of HMs among the sampled soils: Total concentrations of $\mathrm{Zn}, \mathrm{Pb}$ and $\mathrm{Cd}$ varied between 1.8 and 5400, 0.7 and 3440, and 0.2 and $75 \mathrm{mg} \mathrm{kg}^{-1}$, respectively. Mean concentrations of the studied elements in the soils decreased in the order of $\mathrm{Zn}>\mathrm{Pb}>\mathrm{Cd}$. Average global values for total $\mathrm{Zn}, \mathrm{Pb}$ and $\mathrm{Cd}$ in uncontaminated soils are about 80-120, 20-100 and 1-5 $\mathrm{mg} \mathrm{kg}^{-1}$, respectively (Adriano 2003; Kabata-Pendias 2010). The mean values of the studied HMs contents in the studied soils were significantly higher than those for non-contaminated soils (Table 1). Thus, the studied area can be considered as a polluted site, requiring specific management strategies for preventing the spread of HMs pollution.
For all metals, the total concentrations showed a great degree of variability, indicated by large coefficients of variation $(\mathrm{CV})$ from $234.2 \%$ of $\mathrm{Cd}$ to $354.8 \%$ of $\mathrm{Pb}$. The elevated CVs reflected the non-homogeneous distribution of concentrations of anthropogenically emitted HMs. It has been reported that $\mathrm{CV}$ values of HMs dominated by natural resources are relatively low, while $\mathrm{CV}$ values of $\mathrm{HMs}$ affected by anthropogenic resources are quite high (Han et al. 2006). Accordingly, $\mathrm{Zn}, \mathrm{Pb}$ and $\mathrm{Cd}$ contents in soils tend to be affected by anthropogenic activities in the Zinc Town of Zanjan. In other words, the observed high CV values of the measured HMs may show a primary evidence for the effect of Zinc Town HMs on the pollution status in the surrounding lands.

Large standard deviations were found in the studied $\mathrm{HMs}$ except $\mathrm{Cd}$. This also indicated a wide range of concentrations in the studied soils. The distribution of concentrations was skewed by a small number of large values (contamination hot spots). These outliers lead to high positive skewness and consequently serious violation from the normal distribution (Table 1). The results of the $\mathrm{K}-\mathrm{S}$ test $(P<0.05)$ confirmed that the concentrations of the measured HMs were not normally distributed (Table 1). Therefore, the row data of the HMs concentrations were transformed by natural logarithm to a normal distribution prior to geostatistical analyses.

The $\mathrm{Zn}, \mathrm{Pb}$ and $\mathrm{Cd}$ contents of plants in this study ranged from 4.5 to $960.2,2.5$ to 380.5 and 0.4 to $8.4 \mathrm{mg} \mathrm{kg}^{-1}$, respectively. These contents are also higher than their typical contents in the plants (Adriano 2003), but according to Baker and Brooks (1989), the studied plant species does not match the requirements of the hyperaccumulator plants. Notably, $\mathrm{Zn}$ and $\mathrm{Pb}$ hyperaccumulation does not occur in most plants, say $\mathrm{Pb}$ - and $\mathrm{Zn}$-contaminated soils (Wenzel and Jockwer 1999; Reeves et al. 2001). The majority of $\mathrm{Zn}$ and $\mathrm{Pb}$ hyperaccumulators have been reported from Europe (Reeves and Baker 2000). Analyzing

Table 1 Summary statistics of total concentrations $\left(\mathrm{mg} \mathrm{kg}^{-1}\right)$ of studied HMs in the soil and plant samples

\begin{tabular}{|c|c|c|c|c|c|c|c|c|}
\hline Variable & Mean & Minimum & Maximum & Coefficient of variation (\%) & Standard deviation & Skewness & Kurtosis & $\mathrm{K}-\mathrm{Sp}^{\mathrm{a}}$ \\
\hline \multicolumn{9}{|l|}{ Soil } \\
\hline $\mathrm{Zn}$ & 294.2 & 1.8 & 5400 & 297.6 & 875.44 & 3.54 & 12.51 & 0 \\
\hline $\mathrm{Pb}$ & 152.8 & 0.7 & 3440 & 354.8 & 542.16 & 4.39 & 20.23 & 0 \\
\hline $\mathrm{Cd}$ & 5.6 & 0.2 & 75 & 234.2 & 3.26 & 3.18 & 9.88 & 0 \\
\hline \multicolumn{9}{|l|}{ Plant } \\
\hline $\mathrm{Zn}$ & 131.4 & 4.5 & 960.2 & 161.7 & 212.41 & 2.43 & 5.41 & 0.001 \\
\hline $\mathrm{Pb}$ & 113.2 & 2.5 & 380.5 & 90.3 & 102.2 & 0.8 & 0.54 & 0.11 \\
\hline $\mathrm{Cd}$ & 2.5 & 0.4 & 8.4 & 77.4 & 1.95 & 1.08 & 0.23 & 0.035 \\
\hline
\end{tabular}

${ }^{a} \mathrm{~K}-\mathrm{Sp}$ : statistics of Kolmogorov-Smirnov test at significance level $95 \%$ 
HMs concentration in natural plants collected from a contaminated site in the Central Iran, Ghaderian and Ghotbi Ravandi (2012) reported that just one of the different studied plant species may be considered as the hyperaccumulator for HMs. Whether or not the plants species grown in the contaminated soils at the present study are physiological races of metal-tolerant species requires further investigation and experimentation.

Similar to soil samples, mean concentrations of studied HMs in the plant samples decreased in the order of $\mathrm{Zn}>\mathrm{Pb}>\mathrm{Cd}$, with the values of $131.4,113.2$ and 2.5, respectively. This similarity may be considered as an evidence for the impressibility of the HMs distribution pattern in plant communities from their variability pattern in the basement soil. Mean concentrations of $\mathrm{Zn}$ and $\mathrm{Cd}$ in the plant samples are about half of their total contents in the soil (Table 1). Although simple relationships are seldom found in natural soil systems between plant metal levels and total metal concentrations in soils (Qian et al. 1996), regarding the relatively low values for the ratio of metal content in plant to soil, it is logical and probable that all the plant $\mathrm{Zn}$ and $\mathrm{Cd}$ uptakes are ensured by soil. However, for $\mathrm{Pb}$, the ratio of metal content in plant to soil increases to about $3 / 4$. Considering that the high proportion of the total $\mathrm{Pb}$ is an insoluble fraction not immediately bioavailable for plants (Kopittke et al. 2008), founding another source of $\mathrm{Pb}$ in the studied area seems to be inevitable. Totally, metal pollutants mainly enter the plant system through the soil or via the atmosphere (Uzu et al. 2010). Because of its strong binding with organic and/ or colloidal materials, it is believed that only small amounts of lead are available in the soil for plant uptake (Punamiya et al. 2010). On the other hand, airborne contamination of plants by lead was evidenced in previous studies (Tjell et al. 1979; Kozlov et al. 2000; Uzu et al. 2010). Hence, it seems that contaminated dusts arising from metal smelting activities in Zinc Town may somewhat have added to the elevated $\mathrm{Pb}$ concentration in the natural plants grown in the surrounding lands. However, accurate portioning of HMs of different resources requires further investigation.

\section{Spatial structure analysis of HMs}

The spatial behaviors of the selected HMs in the soil and plant samples were evaluated through their variogram surfaces and semivariograms analyses. Since the variogram surfaces did not show any spatial anisotropy (not shown), omnidirectional variograms for the studied HMs in the soil and plant samples were calculated and fitted to a spherical model (Fig. 2). This fitted model was chosen due to the lowest RMSE in comparison with other possible models. The parameters and cross-validation results for fitted spherical models are presented in Table 2.
As presented in Table 2, the range of the optimal model for all the soil and plant HMs concentration data varied between 2100 and $2850 \mathrm{~m}$. This key parameter, which is a function of scale, the distance between sample points and position of landscape (Cambardella et al. 1994), establishes the outer limit at which points in space still interact spatially (Webster and Oliver 2001). Knowledge of the range of influence for various properties allows construction of independent datasets for classical statistical analysis. However, the range of all variables was exceeded $500 \mathrm{~m}$, indicating the presence of spatial structure beyond the original sampling distance. This finding can be a good indicator of decrease in the sampling density for pollution monitoring in the future.

The spatial dependency levels for the selected variables were evaluated by the ratio of the random variance (nugget) to total variance (sill) multiplied by 100 , namely relative nugget effect (Cambardella et al. 1994). For the ratio of $<25 \%$, the variable was considered to be strongly dependent on space, or strongly distributed in patches; for the ratio between 26 and $75 \%$, the variable was considered to be moderately dependent on space; and for the ratio $>75 \%$, the variable was considered to have a weak spatial dependency. The results of this study showed that all the soil and plant HMs contents have moderate spatial dependency level (Table 2), although some differences exist between soil and plant data. RNE values in soil data were quite close to threshold value 25 , but these values increased in plant data except for $\mathrm{Zn}$. This observation might indicate that $\mathrm{OK}$ had slightly better performance in soil community compared to plant community. Other researchers have reported moderate spatial correlation class for different HMs in the soil (Wu et al. 2008; Karanlik et al. 2011; Dankoub et al. 2012).

As shown in Table 2, HMs distribution pattern in plant samples was similar to the spatial variability pattern of HMs in the soil too. Having the same spatial dependency level and spatial variability model and negligible differences in the effective range in the studied soil and plant, the selected HMs seem to have the same impressibility from natural and anthropogenic resources of pollutants through the space in the studied area. Regarding the low correlation between plant metal levels and total metal concentrations in soils (Qian et al. 1996), it can be concluded that whereas HMs pollutants are just derived from natural resources, sameness of the HMs spatial distribution in the plants and soil is less probable. Hence, a high similarity between soil and plant HMs distribution patterns at the present study may indicate that anthropogenic activities have likely brought a large amount of industrial pollutants and as a result affected the spatial variability of selected HMs concentration. 

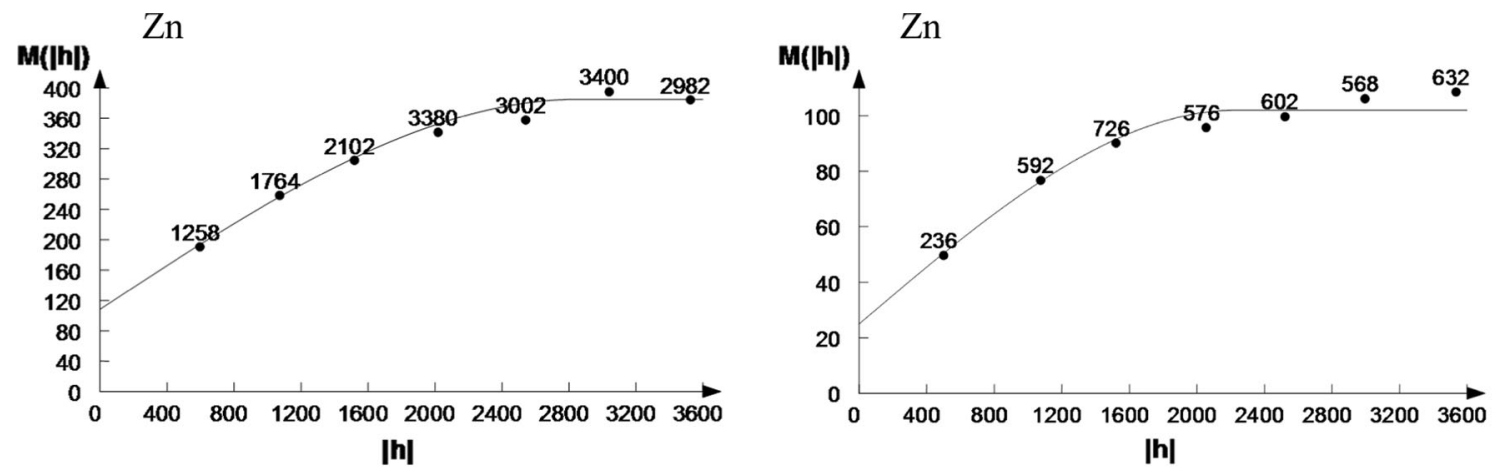

$\mathrm{Pb}$

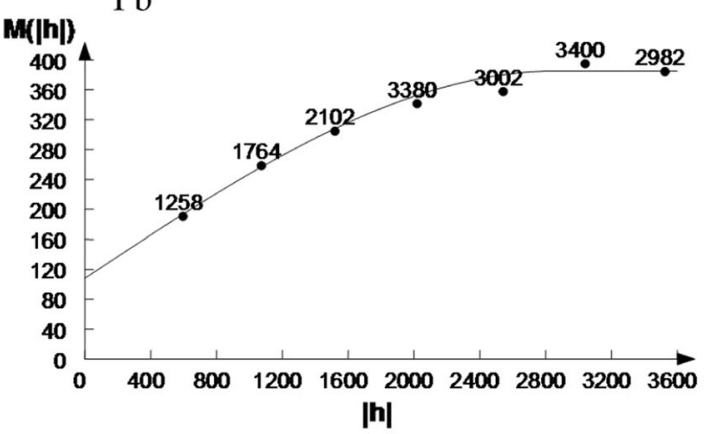

$\mathrm{Pb}$

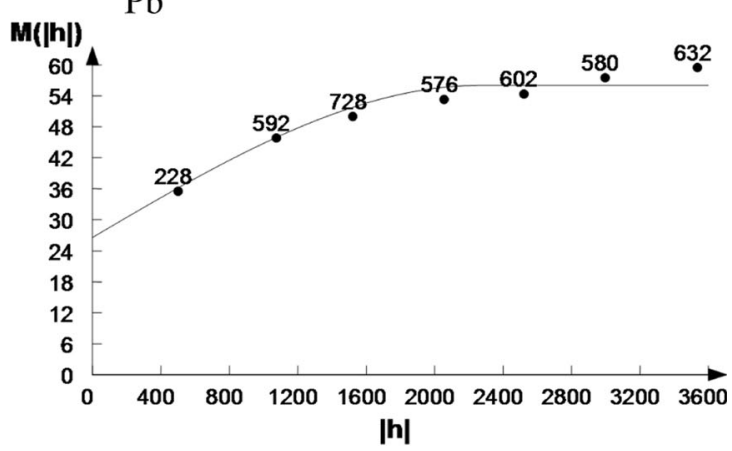

\section{$\mathrm{Cd}$}

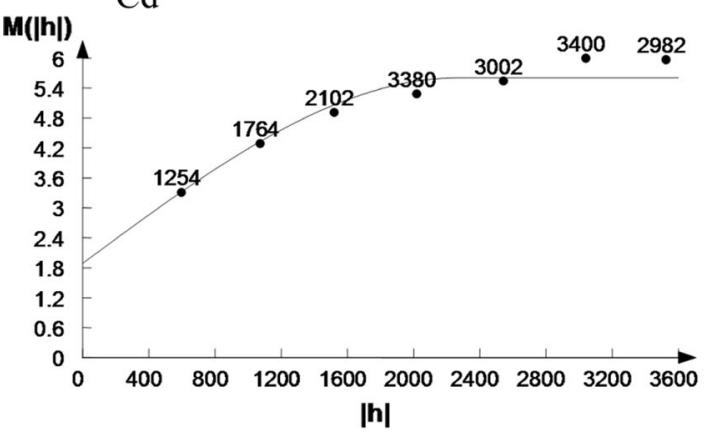

$\mathrm{Cd}$

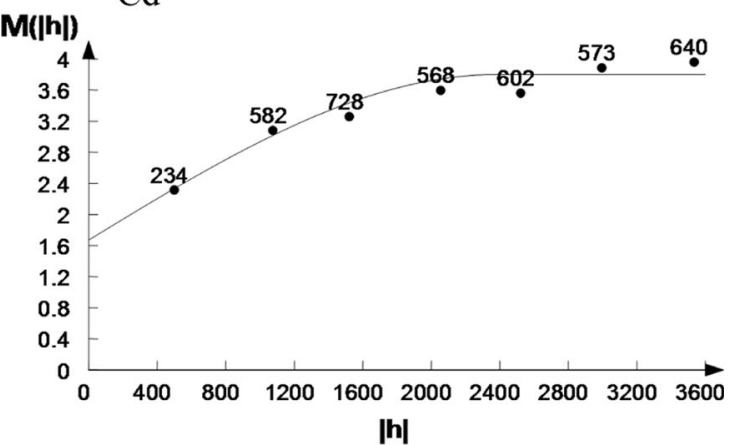

Fig. 2 Omnidirectional variograms for studied HMs in the soil (left) and plants (right)

Table 2 Authorized models, interpolation parameters and cross-validation statistics of soil and plant HMs contents

\begin{tabular}{lllrrlll}
\hline Variable & Model & Range $(\mathrm{m})$ & Nugget & Sill & RNE $(\%)$ & Spatial correlation class & RMSE \% \\
\hline Soil & & & & & & & \\
$\mathrm{Zn}$ & $\mathrm{Sph}$ & 2850 & 108.3 & 385.2 & 28.1 & Moderate & 38.51 \\
$\mathrm{~Pb}$ & $\mathrm{Sph}$ & 2520 & 58.8 & 197.4 & 29.8 & Moderate & 35.23 \\
$\mathrm{Cd}$ & $\mathrm{Sph}$ & 2268 & 1.9 & 5.6 & 33.6 & Moderate & 34.2 \\
Plant & & & & & & & 32.25 \\
$\mathrm{Zn}$ & $\mathrm{Sph}$ & 2100 & 25.7 & 102.2 & 25.1 & Moderate & 28.54 \\
$\mathrm{~Pb}$ & $\mathrm{Sph}$ & 2268 & 26.5 & 56 & 47.3 & Moderate & 30.23 \\
$\mathrm{Cd}$ & $\mathrm{Sph}$ & 2376 & 1.67 & 3.8 & 43.9 & Moderate &
\end{tabular}

Sph spherical, $R N E$ relative nugget effect, $R M S E \%$ standardized root-mean-square error
Effectiveness of soil and plant pollution assessment depends on an accurate and efficient mapping of the pollutants distribution. Based on the spatial structure of the studied variables, predictive capability of applied interpolation method can vary greatly. The cross-validation statistics given in Table 2 shows how well selected 
variables can be estimated by OK method. All RMSE \% values for the studied HMs in the soil and plants are lower than $40 \%$. Hengl et al. (2004) argued that a value of RMSE \% below $40 \%$ means a fairly satisfactory accuracy of prediction. Therefore, the kriging model performed best for all of the selected variables in the studied area. The capability of the $\mathrm{OK}$ interpolator to provide relatively accurate estimations of various soil properties, especially total contents of HMs in the soil, has already been proved (Xie et al. 2011). Our findings support the efficiency of OK in estimating selected HMs contents in the natural plant community.

\section{Spatial distribution of HMs}

Figure 3 shows the spatial distribution of selected HMs for the soil and plant samples created by OK. As shown in Fig. 3, the HMs values significantly differed in different locations. It appeared that the higher HMs values were concentrated mostly in the central parts of the study areathe industrial zones, whereas the lowest soil HMs contents were found in the south and north of the study area. These observations clearly demonstrated that Zinc Town plays a key role in the pollutants distribution in this area. For all studied HMs, total contents in the soil decreased as the distance from Zinc Town increased. Previous researches have justified that HMs distribution in the soil is strongly influenced by various human activities (Facchinelli et al. 2001; Franco-Uria et al. 2009; Cai et al. 2012; Guo et al. 2012; Qu et al. 2013).

The similarity of spatial distribution pattern of different soil HMs (Fig. 3) indicated that these pollutants were strongly controlled by industrial activities. In comparison with $\mathrm{Zn}$ and $\mathrm{Pb}$, some small difference in $\mathrm{Cd}$ distribution pattern was observed (Fig. 3). This observation may indicate lower impressibility of $\mathrm{Cd}$ total contents in the soil from the industrial activities. In other words, it seems that alternative factors like natural resources affect $\mathrm{Cd}$ distribution in the area. However, more studies are required to clarify the relatively accurate portion of all factors controlling the distribution pattern of HMs in this area.

Likewise, the measured $\mathrm{Zn}, \mathrm{Pb}$ and $\mathrm{Cd}$ in plant samples showed high values in the vicinity of Zinc Town, whereas a downward trend was observed when the distance from the pollution source increased (Fig. 3), i.e., duplication of this HMs distribution pattern in the soil. Hence, it can be concluded that Zinc Town controls the spatial distribution of $\mathrm{Zn}, \mathrm{Pb}$ and $\mathrm{Cd}$ not only in the soil but also in other ecosystem components in the study area. These findings clearly highlight the role of industrial activities in simplifying the entrance of dangerous trace elements to the human food chain. Unfortunately, lack of scientific management strategies for controlling the ecosystem pollution by industrial pollutants deteriorates the HMs risks in the area. In accordance with these findings, other researchers have reported some similarities between the contents of the HMs in the soil and plants grown in the vicinity of metal smelter and production factories (Barcan et al. 1998; Ghaderian and Ghotbi Ravandi 2012).

Comparing the trends of studied HMs spatial variability between soil and plant revealed some small differences. Distribution trends of studied HMs in soil were more similar compared to their trends in plant (Fig. 3). This might be due to the complexities of plant uptake process and movement of elements between different parts of plants (Adriano 2003), and this fact that the spatial distribution of elements in plant is more difficult to explain in comparison with soil community.

However, some differences may exist in the distribution pattern of each special HM in the studied soil and plant (Fig. 3). Such differences may reflect a low correlation between total and bioavailable contents of elements in the soil (Kabata-Pendias 2010) as well as existence complexities in plants uptake processes (Adriano 2003). In other words, $\mathrm{Pb}$ distribution in the plant samples is to some extent different from $\mathrm{Zn}$ and $\mathrm{Cd}$ as its maximum levels spread from central parts to the north and northeast of the study area (Fig. 3). Regarding low mobility and consequently low bioavailability of $\mathrm{Pb}$ in soil (Kopittke et al. 2008), these relatively high $\mathrm{Pb}$ levels in plants may result from the presence of $\mathrm{Pb}$ in the industrial emissions, absorbed by aerial plant organs. It has been reported that industrial emissions and dusts contain high concentrations of various HMs, particularly $\mathrm{Pb}$ (Han et al. 2006; Dankoub et al. 2012). Based on other related reports, atmospheric deposition of $\mathrm{Pb}$ (in the emissions from metal processing factories) could make large amounts of $\mathrm{Pb}$ attach to the aboveground parts of the crops (McLaughlin et al. 1999).

The two main purposes of pollution mapping are the analysis of the pollutants spatial structure and identification of the contaminated areas (Xie et al. 2011). Based on the smallness of the calculated estimation error index (Table 2) and logical levels of estimations compatible with actual values of each specific variable (Fig. 3), it can be stated that applied geostatistical method performed well in recognizing the spatial structure of HMs in the soil and plants. In addition, based on the interpolated maps, a maximum of HMs concentrations in plant samples was observed in the areas surrounding Zinc Town, as it was logically expected. Therefore, the OK estimator was able to reveal the spatial distribution pattern of HMs contents in the studied plant samples. 

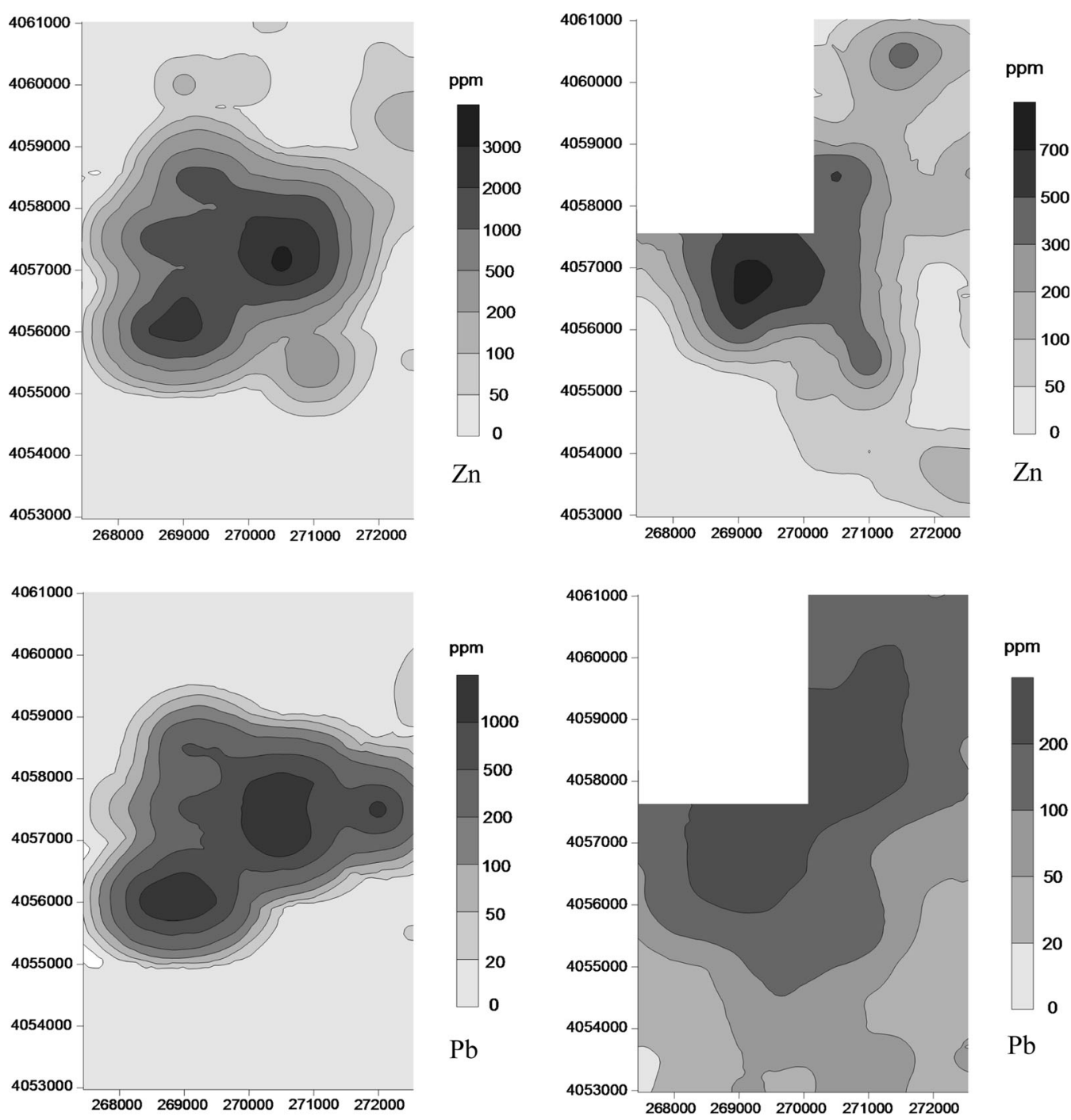

$\mathrm{Pb}$
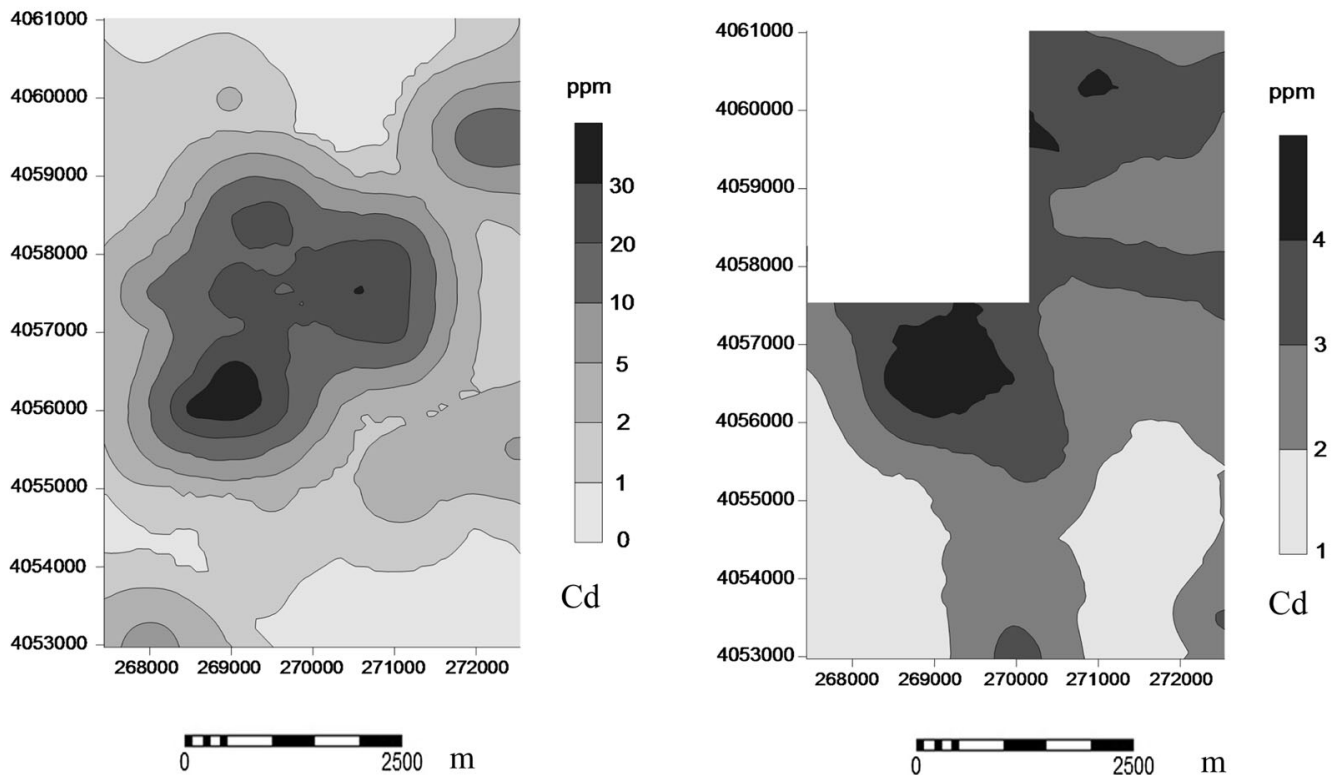
4Fig. 3 Spatial distribution maps of the selected HMs in the soil (left) and plant (right) samples in the study area

\section{Conclusion}

Mean total contents of the soil $\mathrm{Zn}, \mathrm{Pb}$ and $\mathrm{Cd}$ in the studied area were higher than those in non-contaminated soils. Thus, the studied area can be considered as a polluted site, requiring specific management strategies to prohibit the spread of HMs pollution. The highest concentrations of $\mathrm{Zn}$, $\mathrm{Pb}$ and $\mathrm{Cd}$ in the soil and plant samples under study were found in the central parts of the area, around Zinc Specialized Industrial Town. A downward trend in HMs concentration in the soil and plants was observed as a function of the distance from the pollution source. Hence, it can be claimed that the distribution of selected HMs in the ecosystem components is mainly affected by industrial activities in the area. Considering the slightly different distribution pattern of the studied HMs, especially $\mathrm{Pb}$, in the soil and plant samples, it seems that polluted emissions arising from Zinc Town are responsible for elevated HMs contents in natural plants in the study area. However, analyzing HMs contents in the air may provide some useful information about different sources of plant community pollution. Applied geostatistical method has managed to reveal the HMs distribution pattern in the endemic plants grown on polluted soils.

Acknowledgments Financial and technical support for this research by Soil Science Department, University of Zanjan, is acknowledged.

\section{References}

Adriano DC (2003) Trace elements in terrestrial environment: biogeochemistry, bioavailability and risks of metals, 2nd edn. Springer, New York

Alloway BJ (1995) Heavy metals in soils, 2nd edn. Blackie Academic and Professional, London

Alloway BJ, Jackson AP, Morgan H (1990) The accumulation of cadmium by vegetables grown on soils contaminated from a variety of sources. Sci Total Environ 91:233-236

Baker AJM, Brooks RR (1989) Terrestrial higher plants which hyperaccumulate metal elements: a review of their distribution, ecology and phytochemistry. Biorecovery 1:81-126

Barcan VS, Kovnatsky EF, Smetannikova MS (1998) Absorption of heavy metals in wild berries and edible mushrooms in an area affected by smelter emissions. Water Air Soil Pollut 103:173-195

Burger J (2008) Assessment and management of risk to wildlife from cadmium. Sci Total Environ 389:37-45

Cai L, Xu Z, Ren M, Guo Q, Hua X, Hua G, Wand H, Peng P (2012) Source identification of eight hazardous heavy metals in agricultural soils of Huizhou, Guangdong Province, China. Ecotoxicol Environ Saf 78:2-8

Cambardella CA, Moorman TB, Parkin TB, Karlen DL, Turco RF, Konopka AE (1994) Field scale variability of soil properties in Central Iowa soils. Soil Sci Soc Am J 58:1501-1511
Dankoub Z, Ayoubi S, Khademi H, Lu SG (2012) Spatial distribution of magnetic properties and selected heavy metals in calcareous soils as affected by land use in the Isfahan region, Central Iran. Pedosphere 22(1):33-47

Facchinelli A, Sacchi E, Mallen L (2001) Multivariate statistical and GIS-based approach to identify heavy metal sources in soil. Environ Pollut 114:313-324

Franco-Uria A, López-Mateo C, Roca E, Fernández-Marcos ML (2009) Source identification of heavy metals in pastureland by multivariate analysis in NW Spain. J Hazard Mater 165:1008-1015

Ghaderian SM, Ghotbi Ravandi AA (2012) Accumulation of copper and other heavy metals by plants growing on Sarcheshmeh copper mining area, Iran. J Geochem Explor 123:25-32

Goovaerts P (1999) Geostatistics in soil science: state-of-the-art and perspectives. Geoderma 89:1-45

Guo G, Wu F, Xie F, Zhang R (2012) Spatial distribution and pollution assessment of heavy metals in urban soils from southwest China. J Environ Sci 24:410-418

Han YM, Du PX, Cao JJ, Posmentier ES (2006) Multivariate analysis of heavy metal contamination in urban dusts of Xi'an, Central China. Sci Total Environ 355:176-186

Hengl T, Heuvelink GBM, Stein A (2004) A generic framework for spatial prediction of soil variables based on regression-kriging. Geoderma 120:75-93

Hu KL, Zhang FR, Li H, Huang F, Li BG (2006) Spatial patterns of soil heavy metals in urban-rural transition zone of Beijing. Pedosphere 16:690-698

Jing YD, He ZL, Yang XE (2007) Role of soil rhizobacteria in phytoremediation of heavy metal contaminated soils. J Zhejiang Univ Sci B 8:192-207

Kabata-Pendias A (2010) Trace elements in soils and plants. CRC Press, Boka Raton

Karanlik S, Agca N, Yalcin M (2011) Spatial distribution of heavy metals content in soils of Amik Plain (Hatay, Turkey). Environ Monit Assess 173(1-4):181-191

Kopittke PM, Asher CJ, Kopittke RA, Menzies NW (2008) Prediction of $\mathrm{Pb}$ speciation in concentrated and dilute nutrient solutions. Environ Pollut 153(3):548-554

Kozlov MV, Haukioja E, Bakhtiarov AV, Stroganov DN, Zimina SN (2000) Root versus canopy uptake of heavy metals by birch in an industrially polluted area: contrasting behavior of nickel and copper. Environ Pollut 107:413-420

Lesch SM, Corwin DL (2008) Prediction of spatial soil property information from ancillary sensor data using ordinary linear regression: model derivations, residual assumptions and model validation tests. Geoderma 148:130-140

Li J, Lu Y, Yin W, Gan H, Zhang C, Deng X, Lian J (2009) Distribution of heavy metals in agricultural soils near a petrochemical complex in Guangzhou, China. Environ Monit Assess 153(1-4):365-375

Li XY, Liu LJ, Wang YG, Luo GP, Chen X, Yang XL, Gao B, He XY (2012) Integrated assessment of heavy metal contamination in sediments from a coastal industrial basin, NE China. PLoS ONE $7: 1-10$

Li XY, Liu LJ, Wang YG, Luo GP, Chen X, Yang XL, Hall MHP, Guo RC, Wang HJ, Cui JH, He XY (2013) Heavy metal contamination of urban soil in an old industrial city (Shenyang) in Northeast China. Geoderma 192:50-58

Maas S, Scheifler R, Benslama M, Crini N, Lucot E, Brahmia Z, Benyacoub S, Giraudoux P (2010) Spatial distribution of heavy metal concentrations in urban, suburban and agricultural soils in a Mediterranean city of Algeria. Environ Pollut 158:2294-2301

McLaughlin MJ, Parker DR, Clarke JM (1999) Metals and micronutrients-food safety issues. Field Crops Res 60:143-163 
Möller A, Müller HW, Abdullah A, Abdelgawad G, Utermann J (2005) Urban soil pollution in Damascus, Syria: concentrations and patterns of heavy metals in the soils of the Damascus Ghouta. Geoderma 124:63-71

Pang S, Li TX, Zhang XF, Wang YD, Yu HY (2011) Spatial variability of cropland lead and its influencing factors: a case study in Shuangliu county, Sichuan province, China. Geoderma 162:223-230

Punamiya P, Datta R, Sarkar D, Barber S, Patel M, Das P (2010) Symbiotic role of glomus mosseae in phytoextraction of lead in vetiver grass [Chrysopogon zizanioides (L.)]. J Hazard Mater 177(1-3):465-474

Qian J, Shan XQ, Wang ZJ, Tu Q (1996) Distribution and plant availability of heavy metals in different particle-size fractions of soil. Sci Total Environ 87:131-141

Qu MK, Li WD, Zhang CR, Wang SQ, Yang Y, He LY (2013) Source apportionment of heavy metals in soils using multivariate statistics and geostatistics. Pedosphere 23(4):437-444

Reeves RD, Baker AJM (2000) Metal accumulating plants. In: Raskin I, Ensley BD (eds) Phytoremediation of toxic metals: using plants to clean up the environment. Wiley, New York, pp 193-229

Reeves RD, Kruckeberg AR, Adigüzel N, Krämer U (2001) Studies on the flora of serpentine and other metalliferous areas of Western Turkey. S Afr J Sci 97:513-517

Saito H, Goovaerts P (2000) Geostatistical interpolation of positively skewed and censored data in a dioxin-contaminated site. Environ Sci Technol 34:4228-4235

Sun Y, Zhou Q, Xie X, Liu R (2010) Spatial, sources and risk assessment of heavy metal contamination of urban soils in typical regions of Shenyang, China. J Hazard Mater 174:455-462

Thornton L (1999) Bioavailability of trace metals in the food chain. In: The 2nd international Vetiver conference, Bangkok, Thailand

Tjell JC, Hovmand MF, Mosbaek H (1979) Atmospheric lead pollution of grass grown in a background area in Denmark. Nature 280:425-426

Uzu G, Sobanska S, Sarret G, Munoz M, Dumat C (2010) Foliar lead uptake by lettuce exposed to atmospheric fallouts. Environ Sci Technol 44:1036-1042

Webster R, Oliver MA (2001) Geostatistics for environmental scientists. Wiley, Chichester

Wenzel WW, Jockwer F (1999) Accumulations of heavy metals in plants grown on mineralized soils of the Austrian Alps. Environ Pollut 104:145-155

Wu SH, Zhou SL, Yang DZ, Liao FQ, Zhang HF, Ren K (2008) Statistical and geostatistical characterization of heavy metal concentrations in a contaminated area taking into account soil map units. Geoderma 144:171-179

Xie Y, Chen T, Lei M, Yang J, Guo Q, Song B, Zhou X (2011) Spatial distribution of soil heavy metal pollution estimated by different interpolation methods: accuracy and uncertainty analysis. Chemosphere 82:468-476

Zhang CS, Luo L, Xu WL, Ledwith V (2008) Use of local Moran's I and GIS to identify pollution hotspots of $\mathrm{Pb}$ in urban soils of Galway, Ireland. Sci Total Environ 398:212-221 